\title{
Notas sobre o papel da cultura no desenvolvimento em Celso Furtado
}

Notes on the role of culture in the development in Celso Furtado

\section{João Evanio Borba Caetano}

johncaetano13@gmail.com

Universidade Estadual de Mato Grosso do Sul (UEMS)
Fabricio José Missio

fabriciomissio@gmail.com

Cedeplar/ Universidade Federal de Minas Gerais (UFMG)

Resumo: O objetivo do artigo é retomar alguns elementos da análise de Celso Furtado sobre o papel da cultura no desenvolvimento. Para tanto, a partir de elementos da abordagem histórico-estrutural, articula-se inicialmente a conexão entre os conceitos de desenvolvimento, cultura e dependência. Posteriormente, discutem-se as consequências para o desenvolvimento dos países periféricos da ausência de autonomia dos centros nacionais de decisão e o papel da cultura enquanto instrumento de dominação. Por fim, apresentam-se algumas considerações sobre o caso brasileiro. Em termos conclusivos destaca-se a necessidade dos países subdesenvolvidos lutarem pela valorização da cultura local como forma de determinar os rumos do processo social, sendo que o estado tem papel fundamental nesse processo.

Palavras-chave: Celso Furtado; Cultura; Desenvolvimento

\begin{abstract}
The objective of this article is to analyze key elements about the role of culture in the development of Celso Furtado work. In order to accomplish it, we start researching from the historical-structural approach by identifying, initially, the connections between the concepts of development, culture and dependence. Then, it is discussed the consequences of this approach for the development of the peripheral countries, the lack of its autonomy in the decision making centers and the role of culture as an instrument of domination. Finally, it is presented some considerations on the Brazilian case. An important conclusion of this article is that the developing countries should fight for the appreciation of the local culture as a way to determine the direction of the social process, and the State has a fundamental role in this process.
\end{abstract}

Keywords: Celso Furtado; Culture; Development

\section{INTRODUÇÃO}

Além de ter sido um atuante economista brasileiro, Celso Furtado foi um dos mais destacados intelectuais do país ao longo do século XX. Com uma vasta obra literária, com mais de trinta volumes, traduzidos em mais de uma dúzia de idiomas, ganhou destaque não somente no Brasil e na América Latina, como também na Europa e Estados Unidos, onde estudou e lecionou em reconhecidas universidades. 
Mas a sua obra não se esgota no plano teórico. No Brasil, Celso Furtado atuou enquanto homem público integrando órgãos estratégicos para o desenvolvimento brasileiro, entre eles o Banco de Desenvolvimento (BNDE), em 1953; a Superintendência de Desenvolvimento do Nordeste (SUDENE), em 1959; além do Ministério do Planejamento, em 1962. Em 1986, foi nomeado Ministro da Cultura do governo de José Sarney, onde aprofundou suas reflexões sobre o papel da cultura no desenvolvimento econômico, político e social de uma sociedade. Celso Furtado era, portanto, um homem de "ação" e seu pensamento tinha por objetivo a ação prática ${ }^{1}$.

Pode-se afirmar, tanto no plano teórico como na prática, que o autor sempre lutou para construir uma nação dotada de autodeterminação, cujos recursos fossem mais equitativamente distribuídos dentro da população. Para tanto, a partir da concepção de que o desenvolvimento era um processo multidimensional que abrangia a economia, a sociedade, a política e a cultura, o autor deixa de lado qualquer possibilidade de que o desenvolvimento pudesse ser conseguido por meio dos mecanismos de mercado, para afirmar que ele envolvia "uma estratégia de modificação das estruturas", ou seja, um projeto nacional de caráter social e cultural. Ademais, essa estratégia deveria ser planejada, tendo o Estado como um dos atores principais.

Se a análise furtadiana perdeu espaço ao longo das últimas décadas do século XX, em grande parte pela rápida ascensão do neoliberalismo, o que se observa, nas primeiras décadas do século atual, é um resgate do pensamento do referido autor (Szmrecsányi, 2005; Bielschosky, 2006; Saboia e Carvalho, 2007; Araújo et all., 2009; Boianovsky, 2010 e 2015; D'Aguiar, 2013; Coutinho, 2015; Cunha e Britto, 2017), em grande parte porque já se sabe que os resultados do novo modelo de funcionamento dos mercados baseado na concorrência externa, na desregulação dos mercados e nas privatizações têm sido menos positivos do que se esperava a priori. Assim, multiplicam-se os seminários e as publicações com a difícil tarefa de recuperar as principais ideias do autor, dada sua formação erudita e sua interdisciplinaridade na análise do (sub) desenvolvimento brasileiro.

Nesse contexto, o objetivo deste artigo é sistematizar os principais conceitos e elementos da análise furtadiana em relação ao papel da cultura no desenvolvimento. Para tanto, a partir de elementos da abordagem histórico-estrutural ${ }^{2}$, articula-se a conexão entre

\footnotetext{
${ }^{1}$ Nas palavras do autor, “o objetivo da ciência é produzir guias para a ação prática” (Furtado, 1964, p. 22).

${ }^{2}$ Essa abordagem (método) permite uma análise conjunta e interconectada de aspectos econômicos, políticos e sociais em uma perspectiva histórica. Assim, por um lado incorpora uma dimensão temporal no sentido de que destaca a importância do contexto histórico para entender o funcionamento da economia e da sociedade. Ou seja, ao se examinar tendências históricas, enfatizam-se às mudanças de comportamento dos agentes e à trajetória das
} 
os conceitos de desenvolvimento, cultura e dependência. Mais especificamente, busca-se elucidar, na análise furtadiana, as relações entre o desenvolvimento e a cultura, a fim de compreender a “dependência cultural” característica dos países subdesenvolvidos.

Assim, procura-se estabelecer e enriquecer as amarrações que auxiliam a compreensão da abordagem proposta. Ademais, o objetivo não é recuperar as controvérsias sobre o tema, ou mesmo sobre os desenvolvimentos propostos pelo autor, para lançar, eventualmente, uma luz nova sobre elas, mas, sim, resgatar e destacar a originalidade e a atualidade da abordagem.

A justificativa parte da percepção de Furtado quanto à centralidade da cultura no processo de desenvolvimento. Essa é uma percepção original, que amplia as interpretações sobre as causas e os determinantes do desenvolvimento/subdesenvolvimento. Conforme apontado por D'Aguiar (2013, p. 01), em “O estruturalismo latino-americano” Rodríguez (2009) destaca que a produção intelectual de Celso Furtado se distingue de outros pensadores estruturalistas pela peculiaridade do estudo sistemático do elo entre a cultura e o desenvolvimento. Ou seja, evidencia-se nessa abordagem uma perspectiva não determinista, não economicista, que dá grande importância aos fatores extraeconômicos, em contraste com a teoria econômica convencional (BOLAÑO, 2011; MISSIO et al., 2015)).

Para cumprir com o objetivo, o trabalho encontra-se estruturado em três seções, além desta introdução. Na seção 2, são abordadas algumas características históricas e culturais do subdesenvolvimento. Enfatiza-se como a difusão e a implantação do progresso tecnológico nos países periféricos, associada à falta de capacidade de absorção dessa tecnologia, gerou uma relação de dualismo estrutural nessas economias e, consequentemente, um "dualismo cultural", apontadas como essenciais para a compreensão da "dominação cultural" sofrida nestes países. Na seção seguinte, são abordadas as questões relacionadas ao papel da cultura para o desenvolvimento e possíveis alternativas de como superar essa dominação cultural apresentada pelo Brasil e outros países periféricos. Por fim, a última seção apresenta as considerações finais.

instituições, bem como ao exame dos “desequilíbrios" típicos de economia e sociedade em rápida transformação (Bresser-Pereira e Rego, 2001). Por outro, o método incorpora uma dimensão estruturalista ao admitir a existência de particularidades específicas nas economias em desenvolvimento, em especial, nas estruturas institucionais e produtivas, que constituem "gargalos" que restringem o crescimento. Ou seja, a determinação do nível global da utilização dos recursos ocorre sob o contexto de uma estrutura econômica específica. 


\section{CULTURA E DESENVOLVIMENTO: ASPECTOS GERAIS}

Uma importante reflexão do pensamento furtadiano refere-se à "dimensão cultural do desenvolvimento". Segundo Furtado (1964), essa dimensão remete ao processo de mudança social pelo qual um número crescente de necessidades humanas - preexistentes ou criada pela própria mudança - é satisfeito através de uma diferenciação no sistema produtivo decorrente da introdução de inovações tecnológicas.

Nessa abordagem, a cultura não se restringe à sua dimensão artística. Segundo Barbalho (2011), ela se aproxima de conceitos mais amplos definidos pela Sociologia e pela

Antropologia. É, portanto, um sistema de caráter particular (um subsistema próprio), onde uma série de inter-relações necessita ser levada em consideração (FURTADO, 1984).

De acordo com Borja (2013), o sistema cultural abarca relações que lhe são específicas. Nesse contexto, a cultura material é composta pelos bens utilizados tanto para o consumo quanto para a produção; enquanto a cultura não material reside nas relações sociais de produção, na organização política e social, nos costumes, na religião etc. Segundo o autor, Furtado pretende formular um sistema de cultura para analisar os efeitos da inovação tecnológica sobre os demais elementos (não materiais), ressaltando a interdependência entre eles.

Temos a cultura dividida em dois grandes segmentos e o desenvolvimento mais rápido da
base material exigindo adequadas acomodações na superestrutura não material [...] O que
existe de fundamental e comum aos dois modelos é a constatação de que, sendo a cultura
um conjunto de elementos interdependentes, toda vez que em determinadas condições
históricas avança a tecnologia e se desenvolvem bases materiais, todos os demais elementos
serão chamados ajustar-se às novas condições, ajustamentos estes darão origem a uma série
de novos processos, com repercussões inclusive sobre a base material (FURTADO, 1964,
p. 19-19).

Seguindo essa mesma interpretação, Rodriguez (2007) e Barbalho (2011) afirmam que, em essência, através da cultura se manifesta a capacidade criativa do ser humano. Existem, para tanto, três grandes âmbitos do sistema de cultura: i) a cultura material, que se refere a aspectos econômicos e se expressa no progresso técnico e na acumulação de capital; ii) a cultura não material, que incorpora o âmbito sociopolítico, formado pelas ideias e valores relativos às questões dessa índole, assim como pelas ações políticas concretas que ocorrerem à luz e em conexão com essas ideias e valores; e, iii) elementos da cultura não material não considerados no âmbito sociopolítico, que correspondem ao universo de valores que se situam "acima" dos que pertencem ao segundo âmbito (como a reflexão filosófica, a meditação mística, a criação artística ou a pesquisa científica). 
Logo, tanto o imediato dos padrões de consumo e de urbanização quanto a ciência e a tecnologia, seja nos modos específicos da organização política, seja nas formas de interação com as referências simbólicas estrangeiras, são dimensões da cultura e, desse modo, elementos do processo de desenvolvimento econômico e social da nação (PAULA, 2007).

A capacidade criativa do ser humano para combinar e desenvolver as forças produtivas em um contexto cultural depende, portanto, do grau de desenvolvimento das três dimensões anteriormente mencionadas. Assim, fica evidente que o desenvolvimento é um processo mais que econômico, pois está associado ao esforço recorrente aos processos de iniciativa, criatividade e melhorias nos sistemas de incitações, com o distanciamento das decisões que perpetuam as estruturas anacrônicas da aculturação e da dependência (Brandão, 2012).

É necessário, pois, compreender que o papel decisivo da cultura e sua conexão com o desenvolvimento parte do entendimento de que a própria ideia de desenvolvimento comporta uma gama de ambiguidades. Conforme Brandão (2012, p.02-03),

\begin{abstract}
O conceito de desenvolvimento proposto pela obra furtadiana se baseia no estudo de natureza do processo de exercitar opções alternativas frente a uma temporalidade construída mais larga (e não-imediatista), apta de escolhas autônomas, apresentando trajetórias abertas, sujeitas as decisões estratégicas, em ambiente de incerteza, e de diferenciação de poder (de comando sobre o destino) de agentes desigualmente constituídos. Parte de uma perspectiva que o desenvolvimento, necessariamente envolve o tempo e o espaço nas decisões de como alocar (intertemporalmente, interespacialmente, intersetorialmente etc.) ativos, recursos, capacitações, produtivamente ou não, ou seja, envolve a questão da destinação do excedente social.
\end{abstract}

Nesse contexto, Furtado (1978) chama atenção que nessa gama de ambiguidades o desenvolvimento comporta um conjunto de transformações nas estruturas sociais e nas formas de comportamento que acompanham a acumulação do sistema de produção. Ou seja, o desenvolvimento deve ser entendido como um processo cultural e histórico que atende a um sistema de dominação social. Portanto, torna-se indispensável identificar a natureza desse sistema de dominação (seu relacionamento com a estratificação social, seus meios de legitimação, sua organização no espaço, seus meios de reprodução, etc).

Segundo Bolaño (2011), é o sistema global de cultura, assim constituído, o elemento determinante das formas institucionais (sistema de dominação) sobre as quais se desenvolverão as relações de produção e apropriação. Da mesma forma, são determinações de ordem cultural, decorrentes das particularidades de cada formação histórica, que explicam a situação específica das economias desenvolvidas e subdesenvolvidas e sua integração no sistema global. 
Em síntese, o processo de desenvolvimento é caracterizado pelo conflito distributivo, pela dinâmica de ação das facções das classes sociais e é, portanto, indispensável identificar e conhecer os sujeitos sociopolíticos portadores de decisões transformadoras. Diante de tal afirmativa, para fazer frente a tais desafios, é fundamental o papel do Estado e do planejamento para realizar estratégias concretas de desenvolvimento, dotadas de maior racionalidade das decisões que comandam processos sociais, evitando, de tal modo, que apareçam processos cumulativos e não reversíveis em direções não desejadas.

A superação do impasse com que nos confrontamos requer que a política de desenvolvimento conduza a uma crescente homogeneização de nossa sociedade e abra espaço a realização das potencialidades de nossa cultura, a questão central se limita em saber se temos ou não possibilidade de preservar nossa identidade cultural (FURTADO, 2002, p. 36).

A seguir, abordamos o papel da inovação no processo de acumulação de capital, bem como na distribuição do produto, considerando especialmente a situação dos países subdesenvolvidos.

\section{CULTURA, INOVAÇÃO E SUBDESENVOLVIMENTO}

Uma forma de compreender a relação entre cultura e desenvolvimento é retomar aspectos da análise furtadiana sobre a origem $\mathrm{e}$ as características históricas do subdesenvolvimento. Para tanto, é fundamental a reflexão sobre a geração, a difusão e a implantação do progresso técnico, levando-se em consideração as suas raízes históricas e culturais. Dado que a tecnologia é uma das vias mais intensas de mudança cultural dos povos, Furtado aponta para a necessidade de compreensão do processo pelo qual os países geradores de inovação tecnológica influenciam os valores culturais e os padrões de consumo das sociedades ${ }^{3}$.

Sendo assim, a partir do processo de desenvolvimento das forças produtivas, a análise do subdesenvolvimento tenta entender as características econômicas de um determinado sistema nacional e relacioná-las com as estruturas políticas, culturais, sociais e ideológicas. A partir dessa análise, busca-se identificar as formas de produção de excedente e a formação de uma

\footnotetext{
${ }^{3} \mathrm{O}$ avanço do progresso tecnológico nos países centrais, que deu origem a revolução causada nas comunicações com o surgimento e a disseminação da internet e de outros meios de comunicação (como os smarthphones), por exemplo, faz com que as sociedades da periferia gastem exageradamente em bens sofisticados e supérfluos em detrimento da acumulação primitiva de capital. No caso brasileiro, para exemplificar, o que se observa é que a sociedade contemporânea tem sido fortemente influenciada pela indústria cinematográfica e musical estrangeira que, ao reproduzirem os padrões de consumo dos países centrais, induzem o desejo de compra de "bens de marca", tanto no que se refere ao vestuário, quanto a automóveis ( $S U V S)$ e jóias.
} 
classe hegemônica, que posteriormente passaria a direcionar os valores culturais e ideológicos.

A falta de capacidade que os países subdesenvolvidos possuem de absorver plenamente o progresso tecnológico, acrescentada à insuficiente acumulação produtiva, foi primordial para que ocorresse o chamado dualismo estrutural ${ }^{4}$, que, por sua vez, acabou por gerar o que o Furtado descreve como "dualismo cultural". Ou seja, a cisão entre o setor capitalista e o não capitalista também se expressa nas diferentes culturas, material e não material, a que cada um está ligado. Quando a elite de um país subdesenvolvido segue os padrões culturais impostos pelos países desenvolvidos, onde o grau de acumulação é muito mais elevado, a tendência é de aumento do abismo social que separa os incluídos no sistema capitalista e seus excluídos.

Logo, o imediato dos padrões de consumo e de urbanização, a ciência e a tecnologia, os modos específicos da organização política e as formas de interação com as referências simbólicas estrangeiras são dimensões da cultura e, desse modo, elementos do processo de desenvolvimento econômico e social da nação (PAULA, 2007).

O processo de acumulação é o eixo em torno o qual evolui não somente a economia capitalista, mas o conjunto das relações sociais em todas as sociedades em que se implantou a sociedade industrial. A continuidade desse processo requer permanentes transformações nos estilos de vida, no sentido da diversificação e sofisticação. Difundir padrões de consumo, antes reservados a uma minoria, também abre a porta a possibilidade de acumulação. Mas é a discriminação entre os consumidores que permite ao sistema de incentivo alcançar sua máxima eficácia (FURTADO, 1978, p.46-47).

Segundo Jaramillo (2011, p. 261), visto que o processo de industrialização na América Latina ocorreu através da diversificação de padrões de consumo, a falta de acesso ao progresso técnico e seu vínculo limitado com o processo de industrialização faz com que a condição de "subdesenvolvimento" da América Latina, mais do que um problema de atraso em relação aos padrões modernos de desenvolvimento, seja consequência do histórico processo de dependência cultural fruto da adoção do "modelo" sociocultural imposto pelo centro 5 .

Evidencia-se, portanto, a relação que os países centrais, difusores e controladores do progresso tecnológico, têm com os países periféricos no tocante à introdução de novos

\footnotetext{
${ }^{4}$ Esse dualismo pode ser expresso, por exemplo, na questão modernização/marginalização (ver Albuquerque, 2007).

${ }^{5}$ A ideia de reduzido acesso ao progresso tecnológico também é encontrada em Caio Prado Jr. (1972). Segundo o autor, um dos elementos fundamentais característicos de cada atividade em que se concentra a grande exploração é o seu baixo nível de desenvolvimento tecnológico. Esse baixo nível de desenvolvimento tecnológico era consequência do isolamento ao qual a metrópole relegou sua colônia, o que impossibilitou o contato com novas tecnologias e pelo fato de que tal isolamento não era suprido por uma possível educação ou algo nesse sentido.
} 
padrões de consumo, fomentando, assim, uma "dependência cultural" entre o centro e a periferia.

O controle do progresso tecnológico e a possibilidade de impor padrões de consumo, da parte de certas economias, passa a condicionar a estruturação do aparelho produtivo de outras, as quais se tornam dependentes. Essa estruturação se processa de forma a permitir que uma minoria dentro do subsistema dependente esteja em condições de reproduzir os padrões de vida de prestigio criados pelos subsistemas dominantes. Assim, na economia dependente existirá, sob a forma de um enclave social, um grupo culturalmente integrado nos subsistemas dominantes. $\mathrm{O}$ dualismo, tem portanto, desde o início uma dimensão cultural, a qual se traduz, em termos econômicos, numa descontinuidade na superfície da procura. É a industrialização substitutiva de importações, conforme vimos, que transfere essa descontinuidade para a estrutura do aparelho produtivo (FURTADO, 1983, p.183).

Para Borja (2009b), o chamado fenômeno da "globalização" tratou de impor aos Estados componentes do sistema mundial uma uniformização dos modos de vida e dos padrões de consumo. Entrementes, antes da uniformização, ocorreu a difusão de uma determinada cultura, a cultura do centro hegemônico do sistema (claramente representado pelos Estados Unidos da América). Esse processo de difusão é facilitado pela expansão de suas empresas "transnacionais" ou por meio das novas tecnologias da informação e da comunicação, que permitiram acesso quase que irrestrito aos centros difusores dos valores culturais dominantes.

O crescente número de empresas transnacionais foi decisivo na intensificação da padronização do consumo, a partir da introdução de novos produtos e novos processos de produção oriundos do centro do sistema. Neste processo é fundamental ressaltar o papel da propaganda e dos meios de comunicação de massa como instrumento para estimular o consumo da indústria cultural dominante. Tal indústria era basicamente constituída pelas atividades culturais que realizam a reprodução de matrizes em larga escala, composto pelas indústrias cinematográficas e audiovisual, musical e fonográfica e pela literária e editorial, que difundiam de modo massivo os signos e elementos simbólicos da cultura dominante ${ }^{6}$.

Em síntese, segundo Bresser-Pereira (2007), é necessário entender que a industrialização tardia de países como o Brasil é muito diferente da que ocorreu nos países hoje desenvolvidos, porque, enquanto nestes a inovação e a difusão combinam-se para responder às próprias necessidades das sociedades, naqueles, a difusão é marcada pela tentativa de imitação, por parte das elites, dos padrões de consumo do centro. Ainda, segundo o autor, existe um problema que impede o desenvolvimento dos países periféricos, já que as classes beneficiadas pela concentração de renda não se revelam à altura de seu papel. Ao

\footnotetext{
${ }^{6}$ Para uma discussão sobre cultura global do consumo e tradicionalismo local, ver Dalmoro e Nique (2014).
} 
copiarem os padrões norte-americanos de consumo, não poupam para investir e endividam o país no exterior ${ }^{7}$.

A persistência da concentração da renda nas mãos das elites internas condiciona a existência de padrões de consumo que não correspondem ao grau de desenvolvimento alcançado pelas forças produtivas e acabam determinando as duas tendências centrais das economias periféricas: a propensão ao endividamento externo e a propensão à concentração social da renda (GUILLÉN, 2007; BRESSER-PEREIRA, 2007). Assim, se por um lado esse padrão de consumo configura um sistema produtivo funcional, implicando no vazamento do excedente econômico para fins diferentes da acumulação de capital, por outro, ao limitar o crescimento da renda dos trabalhadores e das grandes maiorias, obstaculiza o crescimento do mercado interno e gera tendências à estagnação.

Em outras palavras, o que foi mencionado se manifesta na conformação da "cultura da dependência", que inclui as formas de produção, apropriação e utilização do excedente, a estrutura de poder, as relações sociais e a sociabilidade em um amplo sentido (Borja, 2009).

A compreensão da natureza do subdesenvolvimento passa, então, pelo entendimento da órbita da produção (através das formas específicas de apropriação e realocação do excedente), quanto pela órbita da circulação (pelo uso do excedente resultante da adoção de padrões de consumo conspícuos), pois ambas “engendram a dependência cultural que está nas bases do processo de reprodução das estruturas sociais correspondentes" (FURTADO, 1974, p.80).

Diante de tal conjuntura, o já citado dualismo estrutural, por sua vertente cultural, conduz as classes dominantes dos países periféricos a se identificarem mais com os valores culturais e ideológicos do centro do que com seus próprios valores nacionais. Ou seja, tornase ausente uma identidade que subsidie a formação de uma burguesia nacional, que cultue e exalte suas próprias ideologias e valores. Deste modo, as classes internas controladoras do poder e do capital passam a subjugar as demais classes sociais em nome de uma manutenção de valores alheios a realidade nacional.

Em outros termos, a dominação cultural imposta pelo centro do sistema mundial e a cultura da dependência instituída internamente pelas classes dominantes tornam muito mais complexa, nos países subdesenvolvidos, a consolidação de uma identidade nacional e de interesse comum. Dessa maneira, inviabiliza-se a elaboração e a realização de um projeto

\footnotetext{
${ }^{7}$ Segundo Bresser-Pereira (2007, p. 66): “A acusação de prática do populismo econômico, que essas classes beneficiadas usam para atacar os políticos populares, é indevida, porque é o consumo delas, e não a dos pobres, que leva ao déficit público e, principalmente, ao "populismo cambial"'.
} 
nacional de desenvolvimento que priorize a autonomia dos centros nacionais de decisão e que seja capaz de avançar em direção ao desenvolvimento ${ }^{8}$.

\section{CULTURA E DESENVOLVIMENTO BRASILEIRO}

No intuito de fazer um paralelo histórico sobre o caso brasileiro, a análise deve levar em consideração as suas especificidades culturais, sobretudo em seu processo de colonização, que se iniciou como consequência da expansão da civilização europeia no século XVI, por meio de um ambicioso projeto de expansão mercantil a partir de Portugal,

... preocupando apenas em preservar e ampliar seu patrimônio territorial (...) Nos três séculos de período colonial desenvolveu-se no Brasil uma cultura que, sendo portuguesa em sua temática e estilo, incorpora não apenas motivos locais mas também toda uma gama de valores das culturas dos povos dominados (...) A permanência de certos traços da cultura brasileira explica-se pela estabilidade dos sistema de dominação social latifundiárioburocrático (...) $\mathrm{O}$ distanciamento entre a elite e povo será característica marcante do quadro cultural que emerge nesse período. As elites como que hipnotizadas, voltam-se para os grandes centros da cultura européia (...) O povo era reduzido a uma referencia negativa, símbolo do atraso (FURTADO, 1984, p.21-22)

Na obra de Celso Furtado, é possível identificar, de uma maneira geral (mas não exclusiva e indissociável), três momentos que teriam caracterizado a cultura brasileira ${ }^{9}$. A primeira, presente em quase toda sua obra, está em sintonia com o processo de colonização anteriormente mencionado.

Caio Prado Jr. (1972) já havia identificado, ainda que não explicitamente, o papel determinante que o processo de colonização exerce no sentido de moldar a formação cultural e, portanto, a própria sociedade brasileira e perpetuar algumas de suas características que se prolongam até a atualidade ${ }^{10}$. $\mathrm{O}$ autor define a colonização nos trópicos como "uma vasta empresa comercial", cujo único objetivo é fornecer produtos primários de alto valor para o mercado externo. Tendo como base a produção agrícola e mineradora realizada em grande escala, ela se organiza em torno de "grandes unidades produtoras que reúnem um número relativamente avultado de trabalhadores", recrutados "de outras raças, indígenas do continente ou negros africanos importados" e dirigidos pelo colono branco (Prado Jr., 1972, p. 29 e 31). Evidencia-se, assim, que, no caso brasileiro, a formação cultural é marcada por uma

\footnotetext{
${ }^{8}$ Em conferência no I Encontro Nacional de Política Cultural, em 1984, Furtado defende que "a reflexão sobre a cultura brasileira deve ser o ponto de partida para o debate sobre as opções do desenvolvimento" (FURTADO, 2012, p. 34).

${ }^{9}$ Para uma retrospectiva crítica sobre as políticas culturais no Brasil, ver Barbalho (2011).

10 Segundo Prado Jr. (1972), no processo de colonização brasileira, as raças escravizadas e incluídas na sociedade colonial, mal preparadas e adaptadas, vão formar nela um corpo estranho e incômodo. Ademais, o autor afirma que o processo de absorção se prolonga até os dias atuais e está longe de terminar. É possível, pois, reafirmar a sentença do referido autor passado mais de meio século.
} 
assimetria fundamental, já que o elemento português (em geral, já portador de importante superioridade técnica) foi o único que "continuou a alimentar-se de suas fontes culturais européias" (FURTADO, 1984, p. 20).

Ainda, segundo o autor, sobre tal estrutura ergueu-se nos trópicos "uma sociedade inteiramente original", diferentemente do que ocorreu na zona temperada, onde se formou uma sociedade que, embora com caracteres próprios, guardou semelhanças em relação à do continente europeu donde se originou, revelando-se mesmo "pouco mais do que simples prolongamento dele”. (Prado Jr., 1972, p.27 e 31). Enquanto isso, “[...] os aborígenes e os africanos haviam sido isolados de suas matrizes culturais respectivas e, ao serem posteriormente privados das próprias línguas, perdiam o senso da identidade cultural." (FURTADO, 1984, p. 20).

Em suma, a economia não é uma estrutura de base orgânica (formação de um sistema e meios de mantê-lo), já que a população empregada atende aos objetivos externos aos quais está subordinada.

Segundo Paula (2007), é no século XIX que Furtado localiza o essencial daquele processo de interdição do povo brasileiro por parte de suas elites políticas e culturais. Esse processo de interdição passa por uma série de medidas de repressão (episódio como Cabanos, no Pará; da Sabinada, na Bahia; da Balaiada, no Maranhão; entre outros), de procrastinação (o fato de a Abolição ter sido adiada, bem como o fato de não ter se promovido a reforma agrária) e manipulação (manipulação política produzida pela estrutura de poder do $2^{\circ}$ reinado).

Os demais momentos que caracterizam a cultura brasileira são incidências do século XX. O segundo, que remete aos anos de 1920/1930, está associado à “iniciativa modernista, a qual foi o pedant artístico-cultural de um processo que era também o de definhamento da velha ordem oligárquica" (PAULA, 2007, p. 277).

Há, nesse período, todo um contexto sócio-histórico (crise da economia cafeeira e da República Velha) cujos desdobramentos foram o avanço da industrialização e a Revolução de 30, em estreita consonância com transformações no plano cultural, onde o movimento modernista brasileiro, demarcando uma mudança de postura dos intelectuais, expressa no maior compromisso com a tarefa de compreender a realidade sócio-política brasileira com vistas a transformá-la (IGLÉSIAS, 2007). 
O terceiro momento está associado ao processo de modernização dependente que se acentua no Brasil a partir da segunda metade do século $\mathrm{XX}^{11}$. Observe-se que a Europa da Revolução Industrial, ao promover um brutal aumento da produtividade do trabalho, intensifica a acumulação e aumenta o nível e a diversificação do consumo, ao mesmo tempo em que a nova divisão internacional do trabalho permite a um país especializado em produção agrícola para exportação, "[...] acesso à moderna tecnologia sob a forma de produtos de consumo, sem ter que investir para elevar a produtividade física do trabalho" (FURTADO, 1984, p.22).

A assimetria cultural da sociedade brasileira, numa situação de expansão da demanda internacional que garantia "vantagens comparativas estáticas criadas pela especialização", facilitava a importação de bens sofisticados por parte de uma elite cada vez mais identificada com os valores externos. Esse comportamento imitativo das elites nacionais, decorrente da adesão à "modernização dependente", terá como corolário a redução da cultura do povo brasileiro a "[...] uma referência negativa, símbolo do atraso, atribuindo-se significado nulo à sua herança cultural não européia e recusando-se valia a sua criatividade artística" (FURTADO, 1984, p.23).

Segundo Arend (2008), a matriz institucional brasileira molda os agentes a se comportarem com "emuladores" de estratos sociais mais modernos, rompendo com identidades culturais que poderiam levar ao desenvolvimento econômico do país. Ainda, segundo o autor, a cultura local brasileira não foi destruída, mas ela não é entendida pelas "classes dirigentes" como importantes para o processo de desenvolvimento capitalista brasileiro.

Observe que, de acordo com o pensamento furtadiano, a "modernização" segue os moldes dos países capitalistas e, assim, acarreta um processo de ruptura com a cultura local, o que impõe restrições ao avanço do capitalismo industrial e, consequentemente, do desenvolvimento econômico autônomo. O "desenvolvimento autônomo", baseado nas particularidades locais, não está presente na sociedade brasileira.

O desenvolvimento econômico é dependente da autonomia cultural local. Historicamente, observa-se que as economias que se inseriam no comércio internacional como primário-exportador, em geral, as economias latino-americanas e que em fase subsequente tiveram o seu processo de industrialização, baseado na substituição de

\footnotetext{
${ }^{11}$ Para Furtado (1975, p.98), "uma sociedade só é independente quando há uma independência cultural”.
} 
importações, têm sua "acumulação" de bens culturais em grande parte controlada pelo exterior.

\begin{abstract}
$\mathrm{Na}$ fase em que nos encontramos, de explosão dos meios de comunicação, o processo de globalização do sistema de cultura terá que ser cada vez mais rápido, tudo nos leva a crer que estamos fechando o ciclo que se abriu no século XVI. Todos os povos lutam para ter acesso ao patrimônio cultural comum da humanidade, o qual se enriquece permanentemente. Resta saber quais serão os povos que continuarão a contribuir para esse enriquecimento e quais aqueles serão relegados ao papel passivo de simples consumidores de bens culturais adquiridos nos mercados. Ter ou não ter direito a criatividade, eis a questão (Furtado, 1984, p.25).
\end{abstract}

O desafio civilizatório brasileiro é, então, saber se "continuaremos a contribuir para o enriquecimento do patrimônio comum da humanidade ou seremos relegados ao papel passivo de simples consumidores de bens culturais adquiridos nos mercados. Ter ou não ter acesso a criatividade, eis a questão" (FURTADO, 1999, p.53).

Sendo assim, as estratégias de desenvolvimento efetivas requerem uma ação diretora do Estado sobre o conjunto do sistema econômico e devem ser forjadas em escala nacional. Conforme Brandão (2012, p. 244),

...o desafio político é ganhar o poder de comando sobre os centros de decisões, em uma situação em que alguns poucos "nichos de comando" estão internalizados e a maioria se encontra sobre controle exógeno, e em que há progressivo estreitamento dos horizontes temporais (e da legitimidade) para as ações públicas estruturantes e coordenadoras.

Portanto, para Furtado, o Estado torna-se importante no fomento ao desenvolvimento através de políticas de valorização da identidade cultural, rompendo com a dependência (cultural) instaurada ao longo de todo o processo histórico de colonização e, posteriormente, consubstanciada no processo de "imitação" dos padrões de consumo dos países desenvolvidos (destacadamente, o norte americano).

Em síntese, para Furtado (1974, p. 80), o chamado processo de "modernização" condena o país a um mimetismo cultural esterilizante. A condição fundamental para libertarse do subdesenvolvimento é escapar da obsessão de reproduzir o padrão de consumo daqueles que se auto intitulam como desenvolvidos. É preciso, pois, assumir a própria identidade.

\title{
CONSIDERAÇÕES FINAIS
}

Evidenciou-se, ao longo deste trabalho, que Celso Furtado tratou de maneira ímpar a relação entre a cultura e o desenvolvimento. Sua reflexão sobre a geração, a difusão e a implantação do progresso técnico com as raízes históricas e culturais levou-o a afirmar que a tecnologia é uma das vias mais intensa de mudança cultural dos povos. 
Neste sentido, evidenciou-se a relação de dominação que os países centrais, controladores e difusores do progresso tecnológico, exercem sobre os países periféricos, imprimindo padrões de consumo inadequados às suas realidades. A falta de capacidade para absorver plenamente o progresso tecnológico nos países periféricos acaba constituindo uma estrutura econômica marcada pelo dualismo estrutural (setor moderno/setor atrasado) que, por conseguinte, gera o que Furtado chama de "dualismo cultural". Este, por sua vez, está relacionado com o processo de acumulação desordenado que ocorre na "periferia". Em linhas gerais, o argumento é de que a classe burguesa da periferia tenta imitar os padrões de consumo dos países centrais, enquanto as massas da periferia tendem a imitar a sua elite.

Em um segundo momento, também é apresentado o impacto da globalização na padronização do consumo das massas. Destacou-se o papel exercido pelas empresas “transnacionais" nos países periféricos, bem como a influência da propaganda em veículos de comunicação de massa e o controle da indústria cultural mundial, através das matrizes culturais de larga escala que difundiram de forma massiva os signos e elementos simbólicos da cultura dominante nos países periféricos com intuito de aprofundar a "dominação cultural", afastando-os cada vez mais da sua própria identidade cultural.

Por fim, ressalta-se a questão da valorização da cultura local e seu papel no desenvolvimento. Neste sentido, a invenção estaria diretamente relacionada à criatividade, de maneira que caberia aos países dependentes lutar pelo direito à criação de valores culturais próprios, ligados ao sistema de cultura local, que levariam, consequentemente, à sua afirmação como nação em um cenário global. Ademais, de acordo com o pensamento do autor, o ponto central para o desenvolvimento é a capacidade de determinar os rumos do processo social, com o intuito de alcançar objetivos compatíveis com a identidade cultural e a promoção da invenção cultural. Um país dependente luta pelos valores culturais próprios, ligados à sua cultura local, só assim sendo capaz de se "libertar" culturalmente e de se afirmar enquanto nação em um cenário global. O Estado tem papel fundamental neste processo.

\section{REFERÊNCIAS BIBLIOGRÁFICAS}

ALBUQUERQUE, E. da M. Celso Furtado, a polaridade modernização-marginalização e uma agenda para a construção dos sistemas de inovação e de bem-estar social. In SABOIA, J.; CARVALHO, Fernando Cardim de (Org). Celso Furtado e o Século XXI. Barueri: Manole/Instituto de Economia da UFRJ, 2007.

ARAÚJO, T. P. de; VIANNA, S. W.; MACAMBIRA. 50 Anos de Formação Econômica do Brasil: ensaios sobre a obra clássica de Celso Furtado. (Org.), J. Rio de Janeiro: IPEA, 2009. 
AREND, M. Atraso Via Modernização Cultural: Uma leitura evolucionista das obras de Raymundo Faoro e de Celso Furtado. Brasília: Revista EconomiA, v.9, n.3, p. 651-681, set/dez 2008.

BARBALHO, A. A política cultural segundo Celso Furtado. In BARBALHO, A. [et al.](Org). Cultura e desenvolvimento: perspectivas políticas e econômicas. Salvador: edufba, 2011.

BIELSCHOWSKY, R. Celso Furtado's contributions to structuralism and their relevance today. Cepal Review, vol. 88, p. 7-14, 2006.

BOIANOVSKY, M. 2010. A view from the tropics: Celso Furtado and the theory of economic development in the 1950s. History of Political Economy, vol. 42, no. 2, 221

BOIANOVSKY, M. Between Lévi-Strauss and Braudel: Furtado and the historical-structural method in Latin American political economy. Journal of Economic Methodology, vol. 22, no. 4, 413-38, 2015.

BOLAÑO, C. Indústria e criatividade: uma perspectiva latino-americana. Cadernos do Desenvolvimento, Rio de Janeiro, v. 6, n. 9 pp. 367-382, 2011.

BORJA, B. Cultura e desenvolvimento no pensamento de Celso Furtado. Salvador: V Encontro de Estudos Multidisciplinares em Cultura, maio/2009a.

BORJA, B. Celso Furtado e a cultura da dependência. OIKOS, Rio de Janeiro, v. 8, n. 2, 2009 b.

BORJA, B. Notas sobre a dimensão Cultural em Celso Furtado. In D'AGUIAR, R.F. (Org). Celso Furtado e a dimensão cultural do desenvolvimento. Rio de Janeiro: E-papers: Centro Internacional Celso Furtado, pp. 125-153, 2013.

BRANDÃO, C. Celso Furtado: subdesenvolvimento, dependência, cultura e criatividade. Revista de Economia Política de las Tecnologias de la Información y de la Comunicación, abril/2012.

BRANDÃO, C. Celso Furtado: subdesenvolvimento, dependência, cultura e criatividade. In D'AGUIAR, R.F. (Org). Celso Furtado e a dimensão cultural do desenvolvimento. Rio de Janeiro: E-papers: Centro Internacional Celso Furtado, 258p.,2013.

BRESSER-PEREIRA, L. C.; REGO, J. M. (org). A Grande Esperança em Celso Furtado: ensaios em homenagem aos seus 80 anos. São Paulo: 34, 2001.

BRESSER-PEREIRA, L. C. Celso Furtado: o desenvolvimento como missão. In SABOIA, J.; CARVALHO, Fernando Cardim de (Org). Celso Furtado e o Século XXI. Barueri: Manole/Instituto de Economia da UFRJ, 2007.

COUTINHO, M. Subdesenvolvimento e Estagnação na América Latina, de Celso Furtado. Revista de Economia Contemporânea, vol. 19, no. 3, p. 448-74, 2015. 
CUNHA, A. M. ; BRITTO, G. When development meets culture: the contribution of Celso Furtado in the 1970s. Cambridge Journal of Economics, p. 1-22, 2017.

DALMORO, M. e NIQUE, W. M. Cultura global do consumo e tradicionalismo local. Revista Brasileira de Gestão e Desenvolvimento Regional, v. 10, n. 4, p. 420-442, set-dez/2014,

D'AGUIAR, R. F. (Org). Celso Furtado e a dimensão cultural do desenvolvimento. Rio de Janeiro: E-papers: Centro Internacional Celso Furtado, 258p., 2013.

FURTADO, C. Dialética do Desenvolvimento. Rio de Janeiro: Fundo de Cultura, 1964. .O mito do desenvolvimento econômico. Rio de Janeiro: Paz e Terra, 1974.

1978. .Criatividade e Dependência na civilização industrial. São Paulo: Circulo do Livro, .Pequena introdução ao desenvolvimento: enfoque interdisciplinar. São Paulo: Companhia Editora Nacional, 1980.

. Teoria e Política do Desenvolvimento Econômico. São Paulo: Abril Cultural, 1983.

. Cultura e desenvolvimento em época de crise. São Paulo: Paz e Terra, 1984.

1999.

.O longo amanhecer: reflexões sobre a formação do Brasil. São Paulo: Paz e Terra, . Em busca de um novo modelo: reflexões sobre a crise contemporânea. São Paulo: Paz e Terra, 2002.

Que somos? In: FURTADO, Rosa Freire D'aguiar (Org.). Ensaios sobre cultura e o ministério da cultura. Rio de Janeiro: Contraponto, 2012a. p. 29-41.

GUILLÉN, A. R. A necessidade de uma estratégia alternativa de desenvolvimento no pensamento de Celso Furtado. In: SABOIA, João; CARVALHO, Fernando J. C. (Org.). Celso Furtado e o século XXI. Rio de Janeiro: Instituto de Economia da UFRJ, 2007.

Las huellas del estructuralismo en México: Juan Noyola y Celso Furtado en torno al desequilibrio externo y sus derivaciones teóricas. Cadernos do Desenvolvimento, Rio de Janeiro, v. 12, n. 20, pp. 157-177, 2017.

IGLÉSIAS, F.. Modernismo: Uma reverificação da inteligência nacional. In: ÁVILA, Affonso (Org.). O Modernismo. 3. ed. São Paulo: Perspectiva, 2007. p. 13-26.

JARAMILLO, M. H. A questão rural na América Latina. Subdesenvolvimento ou dependência cultural? Reflexões a partir da obra de Celso Furtado. Cadernos do Desenvolvimento, Rio de Janeiro, v. 6, n. 9, p. 251-266, jul.-dez. 2011. 
MISSIO, F. J.; JAYME JR., F. G. ; Oreiro, J. L. The structuralist tradition in economics: methodological and macroeconomics aspects. Revista de Economia Política (Impresso), v. 34, p. 247-266, 2015.

PAUlA, J. A. História e cultura no pensamento de Celso Furtado. In SABOIA, J.; CARVALHO, Fernando Cardim de (Org). Celso Furtado e o Século XXI. Barueri: Manole/Instituto de Economia da UFRJ, 2007.

RODRÍGUEZ, O. O estruturalismo latino-americano. Rio de Janeiro: Civilização brasileira, 2009.

. Furtado e a renovação da agenda do desenvolvimento. In SABOIA, J.; CARVALHO, Fernando Cardim de (Org). Celso Furtado e o Século XXI. Barueri: Manole/Instituto de Economia da UFRJ, 2007.

SABOIA, J.; CARVALHO, F. J. C. (org.). Celso Furtado e o século XXI. Barueri;. Rio de Janeiro: Manole / IE.UFRJ, 2007.

SZMRECSÀNYI, T. The contributions of Celso Furtado (1920-2004) to development economics. European Journal of the History of Economic Thought, vol. 12, no. 4, 689-700, 2005. 